\title{
LOS AEROPUERTOS DE LA GLOBALIZACIÓN: ESPECTACULARIZACIÓN Y TEATRALIZACIÓN DE LA INFRAESTRUCTURA COMO HERRAMIENTA DE CITYMARKETING ${ }^{1}$
}

\author{
Roberto Díez Pisonero \\ Cándida Gago García \\ Juan A. Córdoba Ordóñez \\ Departamento de Análisis Geográfico Regional y Geografía Física. Universidad Complutense de Madrid \\ rdpisonero@ghis.ucm.es, cgago@ghis.ucm.es, jcordoba@ghis.ucm.es
}

\section{RESUMEN}

En la actual era de la movilidad, los aeropuertos se han consolidado como infraestructuras necesarias de cualquier ciudad global. Más allá de conectar físicamente los lugares, estos ejercen un rol destacado en la consolidación y mantenimiento de las ciudades mundiales, al tratarse también de instalaciones simbólicas, ligadas a prácticas de ocio-consumo dominantes. Se incide en esta segunda cuestión, analizando distintas actividades como las tiendas de lujo y de marcas globales que aparecen en ellos, así como la morfología que han adquirido a través de la denominada arquitectura de vanguardia.

Palabras clave: Aeropuertos, citymarketing, arquitectura de vanguardia, marcas globales, economía de la experiencia.

\section{ABSTRACT}

In the current era of mobility, airports have emerged as infrastructure necessary for any global city. Beyond connecting places physically, they have a prominent role in the

Fecha de recepción: diciembre 2014.

Fecha de aceptación: noviembre 2015.

1 Este trabajo forma parte de los resultados del proyecto «Lugares, imaginarios y movilidades turísticas en tiempos de crisis», financiado por el Ministerio de Ciencia e Innovación. REF.: CSO2011-26527. Los autores agradecen el trabajo realizado por los evaluadores, cuyas sugerencias se incluyen en el texto final. 
consolidation and maintenance of world cities and are symbolic sites linked to the leisure, where consumption acts in a dominant role. We want to focus on the second question, analyzing various aspects such as luxury stores and global brands that appear in them, and their morphology which has been acquired through this so-called modern architecture.

Keywords: Airports, citymarketing, modern architecture, global brands, the experience economy.

\section{INTRODUCCIÓN}

Si Internet y las Tecnologías de la Información y Comunicación (TIC) han tenido y tienen una decisiva influencia en las tendencias globalizadoras (Pedreño, 2007), no podemos olvidar las importantes contribuciones que los modernos sistemas de transporte y, muy especialmente, el sector de la aviación, están desempeñando en esta mundialización. Numerosos autores han reconocido el papel del transporte aéreo en la compresión espacio-temporal que caracteriza al mundo actual y, con ello, su protagonismo como agente de la globalización (Harvey, 1998; Gago, 2003; Derudder y Witlox, 2008).

La generalización del uso del avión ha provocado una nueva espacialidad diferencial, que privilegia a los espacios y a las personas que están intensamente comunicadas. En este sentido, este medio de transporte, debido a su ubicuidad favorece la conexión de espacios aislados por factores físicos (islas, zonas montañosas, etc.), al tiempo que pone en evidencia las condiciones de aislamiento de aquellos territorios que carecen de estas infraestructuras (Gago, 2003; Córdoba, et al., 2007). Así, el avión, como paradigma de la civilización neotécnica, ha revolucionado los conceptos de accesibilidad, centralidad y distancia al haber permitido aproximar los territorios del planeta. Y, aunque no ha abolido las distancias, ha reducido drásticamente el tiempo para salvarlas «permitiendo no sólo la percepción, sino también la materialización de un mundo que se encoge: tanto en el plano físico como en el simbólico» (Córdoba et al, 2007: 46). Consecuentemente, consideramos que aunque la función aérea en un tiempo pasado era algo complementario en la definición de ciudad, hoy se ha convertido en algo totalmente necesario para posicionar cualquier ciudad en el mapa global. De este modo podría pensarse que no existe ciudad global sin un aeropuerto con una conectividad geográficamente variada e intensa (aeropuerto global), y viceversa, pues ambos elementos interaccionan, se apoyan y retroalimentan.

La relevancia del transporte aéreo es visible en distintas escalas de análisis, pues tanto los datos mundiales como regionales, muestran, en general, una evolución positiva y constante durante las últimas décadas (salvo los periodos de crisis, como el iniciado en 2008). Se han contabilizado 2.977 millones de pasajeros aéreos en el mundo (IATA, 2012) siendo las regiones asiática, norteamericana y europea, las grandes regiones mundiales por número de usuarios (947,9 millones, 808,1 millones y 780,6 millones, respectivamente). Además, la liberalización del sector, iniciada en la década de 1980, aunque no generalizada, ha permitido entre otros procesos, la multiplicación de conexiones y frecuencias aéreas por todo el globo. Asimismo, el abaratamiento tarifario y, por consiguiente, su popularización han hecho que en muchos países este transporte pierda su carácter elitista y minoritario, para pasar a ser más accesible a estratos de población cada vez más diversificados, que identifican el progreso con la movilidad (Bauman, 2001; Córdoba et al., 2007). 
Es sabido que el tráfico aéreo, al igual que el marítimo y, a diferencia del terrestre o el ferroviario, no necesita una red física de infraestructuras para llevar a cabo los desplazamientos. Sin embargo, requiere unas instalaciones que materialicen su actividad. Estas pueden ser desde pequeños aeródromos (localizados en mitad de la selva) hasta grandes infraestructuras por las que transitan millones de personas anualmente y que ocupan amplias extensiones de las ciudades. Con respecto a esta última idea, el aeropuerto más transitado del mundo es el Hartsfield-Jackson Atlanta International, que en 2013 registró más de 94 millones de pasajeros, gran parte de ellos de carácter doméstico. El aeropuerto con más pasajeros internacionales en ese mismo año fue el London-Heathrow Airport, con más de 66 millones. Igualmente, muchos aeropuertos ocupan superficies considerables de la ciudad; por ejemplo el Dubai-International, uno de los más extensos del mundo, tiene una superficie de $56 \mathrm{~km}^{2}$, lo que supone el equivalente a unos 56.000 campos de futbol.

Estas cifras ofrecen una idea de la entidad que tienen estos equipamientos tanto en relación con las personas que los transitan (los usuarios del aeropuerto de Atlanta suponen el equivalente a 17 veces la población de la cuidad), como por la magnitud física que adquieren. Pero, además de satisfacer las necesidades aeronáuticas (aterrizajes y despegues) y materializar los efectos espaciales y territoriales del transporte aéreo (accesibilidad, acortamiento de las distancias, etc.), las infraestructuras aeroportuarias han adquirido protagonismo en función de la imagen que proyectan del lugar y por las actividades asociadas que se desarrollan tanto dentro como fuera del recinto.

En relación con la imagen del lugar, puede decirse, que algunos de ellos se han convertido en importantes estrategias de citymarketing que ayudan a la proyección internacional de la ciudad, al tratarse de instalaciones simbólicas, donde se desarrollan algunas dinámicas culturales, ligadas al ocio-consumo, propias de la globalización. Se trata, además, de instalaciones que forman parte de la imagen que la ciudad proyecta al mundo, donde en un contexto económico neoliberal y de competitividad urbana es importante, incluso vital para las economías locales, regionales y nacionales, la atracción de flujos de todo tipo (capital, trabajadores, turistas e ideas, entre otras). Precisamente son estas funciones, muchas de carácter simbólico y que están ligadas a los servicios que se ofrecen, más que a la logística del sector aéreo, en las que se incide en las siguientes líneas. Se intentará demostrar que en la actualidad son elementos clave para un entendimiento complejo de estas infraestructuras.

En este sentido, la idea principal que se pretende demostrar es que la imagen, identidad $\mathrm{o}$ «marca» de un aeropuerto contribuye a incentivar el valor simbólico de la ciudad y, por consiguiente, a posicionarla en el mapa global. No debe olvidarse que alcanzar el estatus de ciudad global se ha convertido en una prioridad estratégica para las autoridades de muchas ciudades, donde sus instituciones de gobierno se convierten en empresas en búsqueda de atracción de capitales (Jessop y Sum, 2000), y que en este empeño juegan un papel esencial tanto las industrias creativas, como el desarrollo de una sociedad de ocio-consumo. Hay autores que apuntan, además, que el cambio de modelo productivo obedece a una reinvención de la ciudad, donde el consumo juega un papel fundamental en su configuración, no sólo como un elemento económico, sino también desde el punto de vista de la experiencia de los consumidores (Miles, 2012).

Además de esta introducción, el artículo se estructura en tres apartados. En el siguiente se analiza el rol del aeropuerto en el contexto global y las transformaciones recientes 
que está experimentando. Posteriormente, se evaluará su significado simbólico entendido como una estrategia de branding. El trabajo se cierra con las conclusiones más relevantes.

\section{EL AEROPUERTO EN LA GLOBALIZACIÓN: TRANSFORMACIONES RECIENTES}

Ya se ha señalado que el aeropuerto, en la actualidad, constituye una de las estaciones de transporte más complejas y dinámicas, como consecuencia de la importancia que tiene para nuestro estilo de vida el transporte aéreo (Budd, 2002; Dvir y Pasher, 2004). Un aeropuerto de altas prestaciones es un factor esencial de competitividad, una herramienta al servicio del desarrollo económico local y regional. Se considera que una infraestructura de estas características permite dotar a las regiones donde se asientan de prestigio, reputación, centralidad, funcionalidad e internacionalización. Disponer de un hub ${ }^{2}$ aeroportuario internacional se ha convertido en un capacitador de funciones de dirección basadas en el «conocimiento» que favorece el posicionamiento de la ciudad en la jerarquía global (Smith y Timberlake, 2001). En este sentido, además de un hito en el paisaje urbano, se consolida como un potente imán de flujos de capital, conocimiento, ideas e innovación (Dvir y Pasher, 2004).

En relación con esta idea, los estudios que ahondan en el perfil del usuario de transporte aéreo indican que pese a las posibilidades de hacer negocios a través de las nuevas tecnologías, el uso de estas últimas cumple funciones de implementación y complementación más que suplantar las entrevistas cara a cara. El informe Recruitment Confidence Index señala que el $20 \%$ de las compañías dicen que es importante o muy importante que sus ejecutivos realicen desplazamientos y pasen tiempo en el extranjero ${ }^{3}$. De ahí que la toma de decisiones y el intercambio de ideas siga siendo una cuestión física que depende del desplazamiento de altos directivos, científicos, personas de negocios y trabajadores altamente cualificados.

De hecho, el servidor GDS ${ }^{4}$ Amadeus, uno de los líderes mundiales en el sector de reservas de vuelos, señala que dos de los grupos principales de usuarios que incrementarán la demanda internacional son los «commuters cosmopolitas» y los «ejecutivos globales». Los primeros consisten en un amplio y creciente grupo de trabajadores altamente cualificados que desempeñan su trabajo lejos del lugar de residencia y que se ven obligados a viajar semanal o quincenalmente. En cuanto a los segundos, son altos ejecutivos (políticos, inversores, directivos) que hacen viajes de media y larga distancia por motivos de trabajo en clases Business o Premium (Amadeus, 2005).

2 A pesar de la falta de consenso sobre lo que constituye un «hub» (Button, 2002), estos lugares tienden a ser centro de continua investigación (Brueckener y Zhang, 2001; Derudder et al., 2007; Lipovich, 2012). Un «aeropuerto-hub» es un intercambiador integrado de transporte aéreo que concentra y centraliza gran parte del tráfico para realizar una función emisora y/o receptora de diferentes orígenes/destinos (spokes) para redistribuirlos, canalizarlos y redireccionarlos desde y hacia otros centros de aporte y dispersión (Antón Burgos, 1992) con el objetivo de optimizar recursos, tiempo y dinero.

3 Recruitment Confidence Index: encuesta a directores y gerentes del Reino Unido sobre las expectativas en la actividad de contratación y las condiciones de negocio. Edita: Cranfield School of Management y el periódico Daily Telegraph.

4 Sistema de Distribución Global (Global Distribution System, en inglés). Se trata de una base de datos capaz de almacenar y actualizar una gran cantidad de información acerca de la oferta que ofrecen un gran número de empresas turísticas y de transporte a nivel mundial. Entre los GDS más importantes, destacan: Amadeus, Sabre o Travelport (incluye Galileo y Apollo), entre otros. 
Desde el punto de vista empírico, existen diversos ejercicios que han estudiado el aeropuerto y su influencia territorial desde una óptica cuantitativa y economicista. Muchos indicadores, incluyendo pasajeros, el número de aeronaves, el tipo de tráfico aéreo y el volumen de carga, se han utilizado para clasificar los aeropuertos y cuantificar su importancia dentro una jerarquía aeroportuaria global, que en muchos casos se ha utilizado como indicador para determinar una jerarquía urbana (Derudder y Witlox, 2005a, 2005b; Bel y Fageda, 2008; Córdoba y Gago, 2010, 2012). Estos estudios ayudan a describir las maneras en que los aeropuertos favorecen a las economías locales, regionales, nacionales e, incluso, internacionales participando las ciudades en la economía global a través de las conexiones aéreas (Keeling, 1995). Como resultado, mucha de la literatura existente sobre ciudades mundiales y globalización se centra en las capacidades que tienen estos nodos para atraer pasajeros y/u otro tipo de movilidad aérea (carga, movimientos de aeronaves, frecuencias, etc.).

Otros trabajos se centran en la influencia económica de los aeropuertos respecto a las áreas territoriales donde se asientan (Neufville y Yajima, 1972; Hakfoort et al., 2001). Algunos datos ilustran este hecho: los más de 88.000 movimientos aéreos que se registraron en 2012 en el aeropuerto de Los Ángeles (EE.UU) supusieron un impacto anual en la economía local de 27.000 millones de \$. Esta cifra constituye aproximadamente el 3,5\% del PIB del área metropolitana. Para este mismo año, el aeropuerto de Madrid contribuye con aproximadamente 5.000 millones de Euros al PIB de la región, lo que supone un 3\% del total. Uno solo de los seis aeropuertos que sirven a Londres, el de Heathrow, contribuyó económicamente con 6.580 millones de Libras, lo que se traduce en un 1,3\% del PIB del área metropolitana.

Otras líneas de estudio se centran en su organización interna. Tradicionalmente, se han interpretado como infraestructuras para facilitar las operaciones aeronáuticas (aterrizaje, despegue y otros servicios requeridos) incluyendo las dotaciones para tal fin (pistas, torres de control, terminales, hangares, etc.) y aunque también se disponía de dependencias para la atención y servicio de los usuarios, éstas no representaban, salvo en casos excepcionales, ni importantes proporciones de superficie, ni de volumen de actividad (personal ocupado en servicios de venta y restauración; volumen de negocio de las tiendas, bares y restaurantes).

Sin embargo, la organización de las actividades en los aeropuertos, especialmente en los más grandes, ha ido transformándose paulatinamente con la aparición de nuevas instalaciones, servicios y fuentes de ingreso, que pueden calificarse como «no aeronáuticas», en algunos casos extendiendo su alcance comercial e impacto económico más allá de los límites físicos de la infraestructura, con funciones no sólo ligadas con el transporte aéreo, sino complementarias y auxiliares.

Esta metamorfosis se materializa en la ampliación de usos comerciales y en un desarrollo muy amplio de otros ligados al ocio, cuya finalidad es acoger y entretener a los pasajeros en los tiempos de espera, a los que debe añadirse aquellos de orden logístico (ferrocarriles, metro, lanzaderas, autobuses, almacenes y hangares, etc.), destinados a dotar de conectividad la creciente actividad económica de las grandes ciudades. Así, la idea empresarial de los aeropuertos modernos va más allá del movimiento de aviones y, como se muestra a continuación, proporciona una gran variedad de oportunidades comerciales e industriales que en muchos casos se extienden más allá de las «vallas» que delimitan sus perímetros. 
Según el Consejo Internacional Aeroportuario (ACI, en inglés), en 2010 se produjeron un total de 101.800 millones de $\$$ de ingresos aeronáuticos a nivel mundial (ACI, 2011). De ellos, el 46,5\% no dependen de la labor principal de gestión de los aeropuertos, sino de los elementos comerciales e inmobiliarios que se generan en el interior y alrededor de los mismos (ACI, 2011). Esta cuantía está próxima al 60\% para África y América Latina/Caribe (Airportsnumbers.com/25-05-2013; Figura 1). Esto no afecta al «lado aire» (airside -terminales, pistas, áreas de servicios-), sino al «lado tierra» (landside), antes dominado por grandes aparcamientos y vías de acceso a la zona trasera de las terminales (Reiss, 2007; Graham, 2009).

Figura 1

FUENTES DE INGRESOS NO AERONÁUTICOS (\% RESPECTO DEL TOTAL)-MUNDO (DIAGRAMA DE SECTORES) Y GRANDES REGIONES MUNDIALES (DIAGRAMA DE BARRAS).
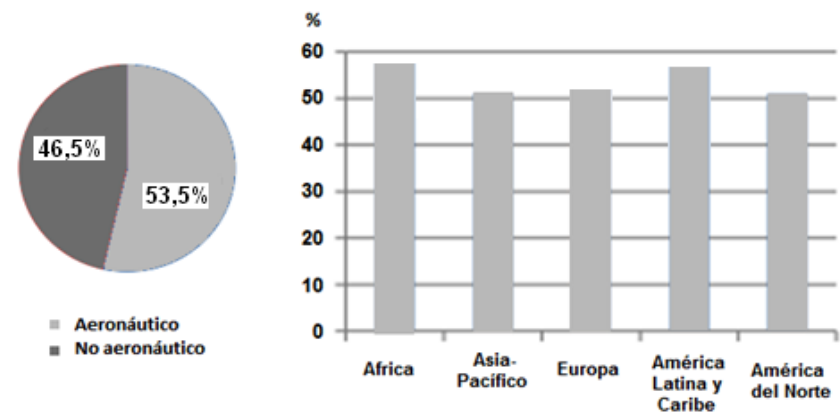

Fuente: ACI, 2011

Debe considerarse, además, la incardinación creciente de los aeropuertos en el entramado relacional y en el plano urbano. En vez de situarse a cierta distancia de las ciudades como sucedía inicialmente, éstos han sido engullidos por la mancha urbana propia del proceso de metropolización contemporánea; además se desarrollan importantes obras de infraestructura (autopistas, líneas de ferrocarril o metro) que los conectan con los centros urbanos. Atrás quedan esos emplazamientos aislados en terrenos de zonas rurales periféricas. Estas infraestructuras ejercen una influencia cada vez mayor en la evolución y el progreso de las áreas metropolitanas, abandonando su concepción tradicional como simple lugar aeronáutico y adoptando otro más rico e interesante como uno de los polos rectores del desarrollo urbano del siglo XXI ${ }^{5}$ (Gago, Serrano y Díez Pisonero, 2015).

Adedibu examinó los cambios en los usos comerciales adyacentes al Jacksonville International Airport en Florida, notificando el papel que los aeropuertos juegan como iniciadores de esos cambios. Considera que «cerca de cualquier aeropuerto se dan influencias que hacen cambiar los usos adyacentes» y que a medida que un aeropuerto aumenta en tamaño, su impacto en los usos de alrededor es más destacable (Adedibu, 1977: 175). En la Tabla 1 aparecen ejemplos de la evolución de los usos del suelo en los alrededores aeroportuarios. Debe decirse que los cambios

5 En España, el interés de los estudios sobre las relaciones entre el aeropuerto y la ciudad se remonta a los años setenta del siglo pasado. El profesor Córdoba (1980) considera que el modelo de aeropuertos que trasciende su función más allá de sus instalaciones es una propuesta de la tercera generación de aeropuertos, configurada por algunos emblemáticos como Dallas-Fort Worth, Paris-Roissy y Montreal-Mirabel. 
no son comparables entre sí, porque los datos proceden de distintas fuentes y han sido obtenidos con metodologías variadas, pero ponen de manifiesto cómo la mancha urbana va integrando pistas y terminales, y cómo los usos industriales y el sector terciario aumentan su presencia ${ }^{6}$.

En los hinterland cercanos a las infraestructuras aeroportuarias es común observar hoteles, centros comerciales y de ocio, boutiques, restaurantes, atracciones culturales y de entretenimiento, parques empresariales, de conferencias y convecciones, sedes de corporaciones, oficinas, actividades de logística y distribución, etc... (Kasarda, 2001; Budd, 2012). En este contexto, el sector terciario ha encontrado en los aeropuertos un lugar idóneo de localización, pues ejercen de potente imán para empresas especializadas en la tecnología de la información y las comunicaciones y otras industrias de alta tecnología, especialmente interesadas en acortar los ciclos de producción y agilizar los tiempos de entrega (just in time) (Timbrel et al., 2006; Yeo et al., 2013). En estas localizaciones pueden identificarse, sobre todo, actividades de I+D, consultoría, servicios informáticos, gestión de recursos humanos, servicios legales, contabilidad, finanzas, marketing y otras áreas de negocio de elevada cualificación.

Tabla 1

CAMBIOS DE USOS DEL SUELO EN ÁREAS CERCANAS A LOS AEROPUERTOS. EJEMPLOS

\begin{tabular}{|c|c|c|c|c|}
\hline & \multicolumn{2}{|c|}{ FECHAS } & \multirow{2}{*}{ CAMBIO EN \% } & \multirow{2}{*}{ FUENTE } \\
\hline BANGKOK & 1994 & 2002 & & \\
\hline $\begin{array}{l}\text { Terciario, residencial y } \\
\text { otros usos urbanos }\end{array}$ & 0,0060 & 5,3 & 5,3 & \multirow{2}{*}{$\begin{array}{l}\text { Swangjang y Iamaram } \\
\text { (2011) }\end{array}$} \\
\hline Uso industrial & 2,6000 & 40,47 & 37,8 & \\
\hline & \multicolumn{2}{|c|}{ FECHAS } & & \\
\hline BANGALORE & 2002 & 2010 & & \\
\hline \multirow[t]{2}{*}{ Espacio construido } & 0,15 & $16,51 \%$ & 16,49 & Mayur et al. (2013) \\
\hline & \multicolumn{2}{|c|}{ FECHAS } & & \\
\hline SCHIPHOL & 1990 & 2006 & & \\
\hline \multirow[t]{2}{*}{ Superficie urbana } & 36.26 & 51.51 & 15,3 & \multirow{7}{*}{$\begin{array}{c}\text { Elaboración propia } \\
\text { a partir de CORINE } \\
\text { Land Cover. Capas, } \\
\text { UMZ } 1990 \text { y UMZ, } \\
2006^{7} .\end{array}$} \\
\hline & \multicolumn{2}{|c|}{ FECHAS } & & \\
\hline DUBLÍN & 1990 & 2006 & & \\
\hline \multirow[t]{2}{*}{ Superficie urbana } & 34,7 & 42,6 & 8,9 & \\
\hline & \multicolumn{2}{|c|}{ FECHAS } & & \\
\hline BRUSELAS & 1990 & 2006 & & \\
\hline Superficie urbana & 57,3 & 60,7 & 3,3 & \\
\hline
\end{tabular}

Muchos de los nuevos polígonos o ciudades empresariales o de negocios están concebidos con el objeto de estimular la producción y la circulación de trabajo abstracto (Cheng et al., 2004), alimentar la renovación de las ciudades y participar en la «economía del conocimiento» (Yigitcanlar et al., 2008). Así, la cercanía a un gran aeropuerto se convierte en un elemento muy importante en las economías de escala que se producen. Además, todos estos usos del suelo son compatibles con una actividad aeroportuaria en las cercanías, pues

6 Freestone (2011) realiza un estudio de caso, al detenerse en el desarrollo que ha tenido lugar en el entorno de los grandes aeropuertos australianos, especialmente en referencia a los cambios en los usos del suelo.

7 El radio empleado para medir el cambio de la superficie urbana alrededor del aeropuerto es de $10 \mathrm{~km}$. 
en ellos no reside población, que por tanto, no tiene que sufrir externalidades negativas nada desdeñables, como el ruido y la contaminación atmosférica o la congestión de tráfico asociada al movimiento de pasajeros y mercancías.

Ante esta realidad, desde el punto de vista académico han aparecido nuevos conceptos que intentan sintetizar la creciente dimensión física que adquieren las infraestructuras aeroportuarias y la multiplicación de actividades que generan: Aerotropolis (Kasarda, 2001), Ciudad aeroportuaria (Guller y Guller, 2003), Pasillo aeroportuario (Schaafsma, 2003), Aviopolis (Fuller y Harley, 2004); Airea (Schlaak, 2010) o AeroSCAPE (Kraffczyk, 2012), entre otros.

Por otra parte, la demanda generada en los hinterlands a la infraestructura, pero sobre todo en cualquier ciudad de orden global, hace que el sector aeronáutico sufra importantes adaptaciones. Debido a ello, se desarrollan alianzas aeroportuarias, para regular el tráfico de conexión (creación de nuevos hubs), y se abren nuevas rutas al tiempo que se cierran aquellas deficitarias.

La relevancia que tiene un aeropuerto para el desarrollo de la ciudad y de su área de influencia (regional o estatal) justifica el importante esfuerzo económico que han realizado Estados, regiones, e incluso gobiernos locales para dotar de infraestructuras aeroportuarias, modernas, competitivas y que multipliquen la capacidad operativa, de acuerdo con las necesidades (Cidell, 2006; Bowel y Cidell, 2011) (Tabla 2) ${ }^{8}$.

Esta doble dinámica, (i) hacia la diversificación de las áreas de negocio relacionadas con los aeropuertos, tanto dentro de la infraestructura como en las áreas aledañas, y (ii) el aumento de la inversión para la remodelación o construcción nuevos recintos, ha sido largamente observada en Estados Unidos (Bazargan y Vasigh, 2003; Van Dender, 2007) y también en Europa (Freathy, 2004; Van Wijk, 2008). Además, la gran previsión de crecimiento en Asia como consecuencia de la liberalización de su espacio aéreo en 2015, augura importantes inversiones fruto también del basculamiento de la actividad económica hacia Oriente (Bowen, 2000; Wang y Hong, 2011).

Tabla 2

INVERSIÓN ECONÓMICA TOTAL DE ALGUNAS AMPLIACIONES AEROPORTUARIAS RECIENTES

\begin{tabular}{|c|c|c|c|}
\hline Aeropuerto & Proyecto & Inaug. & Inversión \\
\hline Madrid-Barajas & Terminal 4 (Nueva) & 2006 & 6.185 millones de euros \\
\hline Londres-Heathrow & Terminal 5 (Nueva) & 2008 & 4.200 millones de libras \\
\hline Beijing Capital & Terminal 3 (Nueva) & 2008 & 3.500 millones de dólares \\
\hline Hong Kong-Check Lap Top & Aeropuerto (Integral) & 1998 & 20.000 millones de dólares \\
\hline Londres-Stansted & Remodelación & 1991 & 400 millones de libras \\
\hline Winnipeg-JAR & Nueva Terminal (Nueva) & 2011 & 200 millones de dólares \\
\hline Osaka-Kansai & Aeropuerto (Integral) & 1994 & 20.000 millones de dólares \\
\hline Doha-Hamad International & $\begin{array}{c}\text { Ciudad aeroportuaria entre } \\
\text { capital y aeropuerto }\end{array}$ & 2022 & 15.500 millones de dólares \\
\hline
\end{tabular}

8 No debe olvidarse la polémica generada ante el gran número de aeropuertos que han aparecido en algunos países en muy poco tiempo. A este respecto, un reciente informe del Tribunal de Cuentas Europeo (ECA, 2014) señala que en algunos países europeos, como España, Italia o Grecia, se han inaugurado en pocos años demasiados aeropuertos y que muchos de ellos no eran necesarios y están sobredimensionados. 
Incluso la remodelación de aeropuertos o la construcción de nuevos se observa en otras partes del mundo. En este sentido, los medios de comunicación recogen ampliamente la instalación de un nuevo aeropuerto en Ciudad de México; este ha sido planificado con una capacidad máxima de 120 millones de pasajeros anuales, para lo que se realizará una inversión de unos 120.000 millones de Pesos (8.800 millones de \$ aprox.). Para valorar la magnitud de esta inversión puede señalarse que la cifra superaba el PIB de 55 países en 2014, siendo similar al de Haití, Tayikistán, Ruanda o Bahamas.

Las ideas expuestas hasta el momento interpretan la magnitud y características físicas y funcionales que han adquirido muchos aeropuertos en relación a procesos de movilidad de orden global. Estos se conciben como verdaderas ciudades, con vías de comunicación interna, espacios comerciales y de ocio, constituyendo un puesto avanzado de la globalización, una «ventana al mundo». Sin embargo, a nuestro juicio, los análisis disponibles se detienen mucho menos en las connotaciones simbólicas que adquieren y que, sospechamos, son clave para un entendimiento completo de estas infraestructuras. Consideramos que su representatividad, imagen y marca también contribuyen a incentivar el valor simbólico de las ciudades y, por consiguiente, a posicionarlas en el mapa global; además esta idea se hace más relevante, si se quiere, al considerar el espacio urbano en su conjunto, donde el aeropuerto aparece inserto dentro de las dinámicas de ocio-consumo recientes.

\section{LOS AEROPUERTOS COMO LUGARES SIMBÓLICOS EN LA SOCIEDAD DEL OCIO-CONSUMO}

Los aeropuertos no son sólo lugares que cumplen funciones aeronáuticas y que se asocian a la dinamización socio-territorial de las áreas donde se asientan, sino que además, juegan un papel esencial en la constitución, consolidación y mantenimiento de las ciudades mundiales, al tratarse de instalaciones simbólicas, ligadas a las dinámicas culturales recientes, que algunos autores califican de capitalismo cultural cognitivo (Scott, 2008).

La extrema competitividad que existe entre las principales ciudades del mundo por adquirir el calificativo de «global» (Storper, 1997; Porter, 2002; Camagni, 2003, Jessop, 2003; entre otros), lleva a que éstas no sólo se centren en atraer multiplicidad de flujos económicos, sino que requieran formas particulares de capital cultural (símbolos, imágenes) que enfaticen su identidad y su valor cosmopolita. De esta manera, se empieza a dar importancia a la producción cultural de espacio y lugar, como manera de atraer y sustentar los flujos humanos y económicos. Cabe destacar la celebración de eventos deportivos y festivales, así como la construcción de estructuras patrimoniales distinguidas como rascacielos, museos y aeropuertos, entre otros. Estos planteamientos, de corte claramente neoliberal, intentan favorecer la competitividad territorial, y entre sus prácticas se incluye la elaboración de una imagen de ciudad o marca que incida en los rasgos de identidad, enfatizando la distinción, el prestigio, la modernidad y el vanguardismo del lugar (Markusen y Shock, 2006; Fuentes, 2011; Canosa y García Caballero, 2012) .

9 La planificación de corte neoliberal ha sido adoptada por algunos enfoques del urbanismo reciente con el fin de garantizar el crecimiento económico y la competitividad de las ciudades. Sin embargo, una corriente crítica se ha gestado al considerar que, más allá de garantizar el posicionamiento internacional de las ciudades, es necesario garantizar las condiciones de equidad y bienestar social (Moulaert et al., 2010; entre otros). 
Consecuentemente, la arquitectura de autor se ha convertido en uno de los principales mecanismos que se utilizan en las ciudades para competir globalmente (Jencks, 2006; Knox, 2012). Un ejemplo paradigmático de todo ello ha sido la construcción del Museo Guggenheim en Bilbao. Haciendo alusión a este edificio, algunos autores estudian el efecto que tiene la instalación de «edificios estrella» o «singulares», de alto valor simbólico, en las ciudades como elementos de dinamización económica y social, lo que genéricamente se ha denominado «efecto Guggenheim» en alusión a este edificio (Plaza, 2000; Plaza y Harrich, 2010). Por extensión, aunque solo ciertos casos podrían ser comparables con el ejemplo anterior, los aeropuertos se han convertido en elementos donde plasmar este tipo de actuaciones, ya que son recintos transitados por millones de usuarios. Así, puede que un visitante o turista no contemple determinados edificios o monumentos en una localidad o su entorno, pero todo aquel que acceda por vía aérea hará uso del aeropuerto, al ser el lugar de entrada o salida de la ciudad. En este sentido, no debe sorprender que se preste atención a la imagen que en éstos se proyecta, pues en algunos casos el número de personas que los transitan es igual o superior al de los hitos turísticos más visitados (Tabla 3).

Los arquitectos, muchos de ellos de renombre, se esfuerzan en los aeropuertos por conseguir verdaderas obras de arte con el objetivo de reforzar la imagen de la ciudad y del país. Las zonas funcionales y de tránsito, antes sin entidad estética, son sustituidas por prestigiosos «laboratorios» de la arquitectura de vanguardia, donde materiales singulares, formas modernísimas de compleja solución arquitectónica e inspiraciones eclécticas se convierten en los principales elementos para que «lo artístico supere lo funcional» (Figura 2 y Tabla 4).

Tabla. 3

PRINCIPALES HITOS TURÍSTICOS DEL MUNDO POR N N VISITANTES Y PASAJEROS TOTALES DEL PRINCIPAL AEROPUERTO DE LA CIUDAD A LA QUE PERTENECE EL HITO (2013)

\begin{tabular}{|c|c|c|c|c|c|}
\hline Rango & Ciudad & Hitos turísticos & $\begin{array}{l}\text { Visitantes } \\
\text { (Mill.) }\end{array}$ & Aeropuerto & $\begin{array}{l}\text { Pasajeros } \\
\text { (Mill.) }\end{array}$ \\
\hline 1 & Las Vegas & Las Vegas Strip & 39,6 & McCarran Int. & 40,9 \\
\hline 2 & Nueva York & Times Square & 39,2 & J. F. Kennedy Int. & 50,4 \\
\hline 3 & Washington DC & Union Station & 32,8 & Dulles Int. & 21,7 \\
\hline 4 & Boston & Faneuil Hall Marketplace & 18 & Logan Int. & 30,2 \\
\hline 5 & Orlando & Disney World's Magic K. & 17,5 & Orlando Int. & 34,7 \\
\hline 6 & Los Ángeles & Disneyland Park & 15,9 & Los Angeles Int. & 66,6 \\
\hline 7 & Beijing & Ciudad Prohibida & 15,3 & Beijing Capital Int. & 83,7 \\
\hline 8 & Estambul & Gran Bazar & 15 & Atatürk Int. & 51,1 \\
\hline 9 & Tokio & Meiji Jingu Shrine & 14,8 & Haneda Int. & 68,9 \\
\hline 10 & París & Catedral de Notre Dame & 13,6 & Charles de Gaulle & 62,1 \\
\hline \multicolumn{6}{|c|}{ SELECCIÓN DE CIUDADES ESPAÑOLAS } \\
\hline & Barcelona & Sagrada Familia & 3,3 & Barcelona-El Prat & 35,2 \\
\hline & Madrid & Museo Reina Sofía & 3,2 & $\begin{array}{l}\text { A.S. Madrid- } \\
\text { Barajas }\end{array}$ & 39,7 \\
\hline
\end{tabular}

Nota: El orden en que aparecen las ciudades se corresponde con el hito turístico más visitado; se ha seleccionado el principal aeropuerto de la ciudad según número de pasajeros; los datos de Barcelona y Madrid se han obtenido de las Oficinas Municipales de Turismo. Fuente: Revistas Travel and Leisure, Daily Mail y web oficial de cada aeropuerto. 


\section{AEROPUERTO DE HONG KONG}

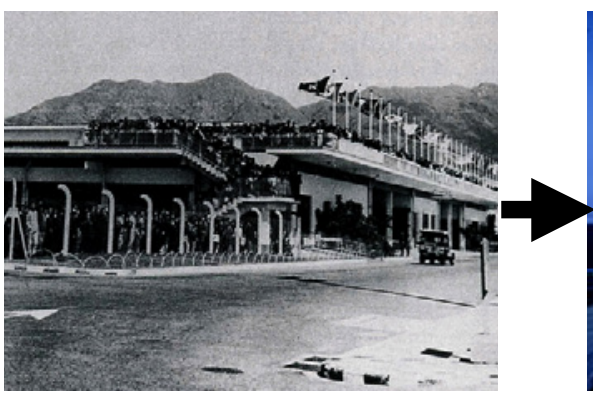

Hong Kong-Kai Tak. Terminal 1. Año 1959 http://www.cad.gov.hk/english/photogallery_60th.htm

\section{AEROPUERTO DE MADRID}

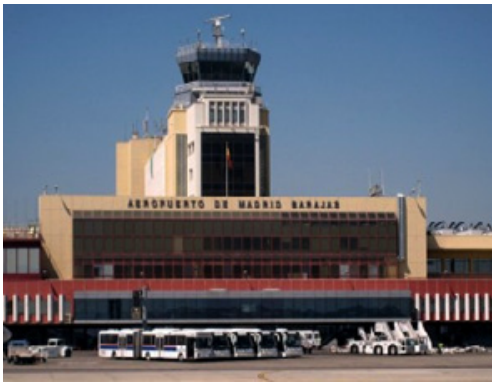

A.S. Madrid-Barajas. Terminales 1,2,3. Años 70s http://www.aeropuertos.net/aeropuerto-de-madrid/

\section{AEROPUERTO DE BEIJING}

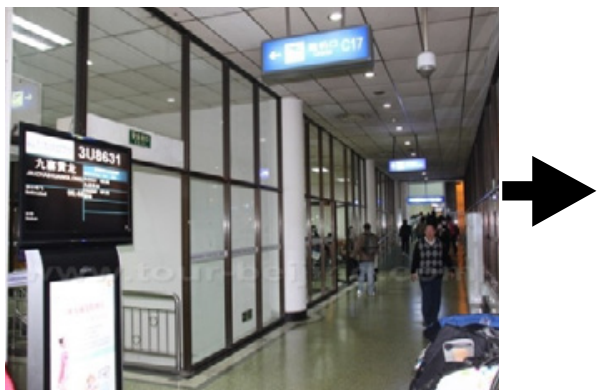

Aerop. Beijing. Terminal 1. Años 60s http://www.tour-beijing.com/blog/tag/chengduairport-shuttle-bus/

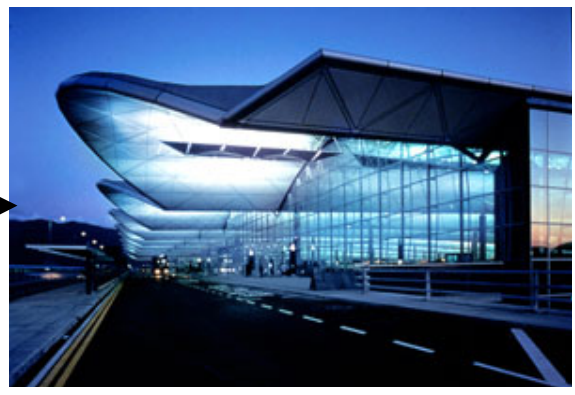

Hong Kong-Chek Lap Tok. Año 1998 http://www.usluk.com/case-studies/nufins/chek-lapkok-airport,-hong-kong/

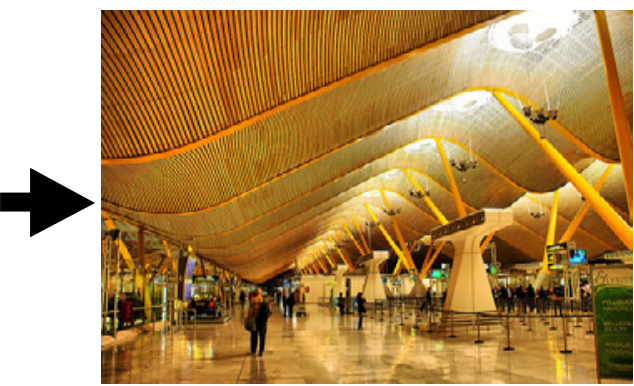

A.S. Madrid-Barajas. Terminal 4. Año 2006 http://www.republica.com/2013/05/22/aena-apuestapor-una-nueva-linea-de-lujo-_654131/

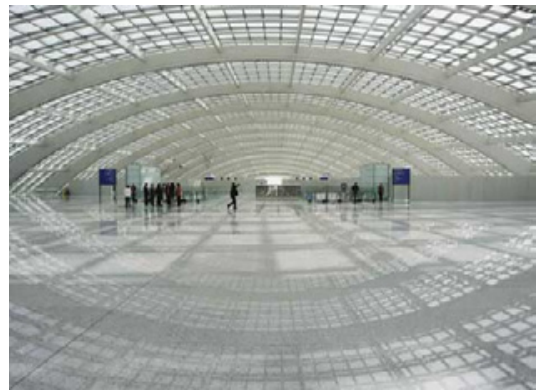

Beijing Internacional. Terminal 3. Año 2008 http://www.brisbanetimes.com.au/ news/travel/beijing-opens-27b-termin al/2008/02/29/1204226971512.html 


\section{AEROPUERTO DE LONDRES}

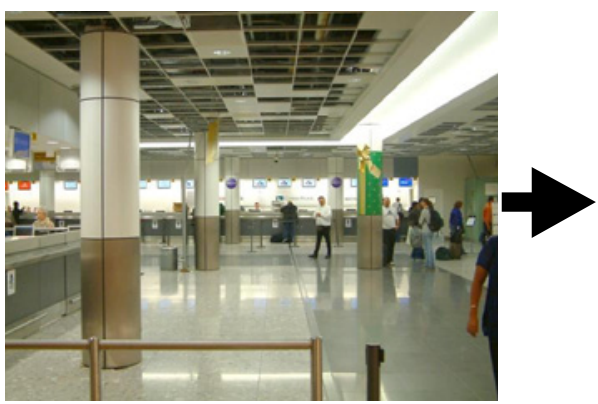

Londres-Heathrow. Terminal 1. Años 60s http://www.leisurestructures.co.uk/pendock_case_ studies.php

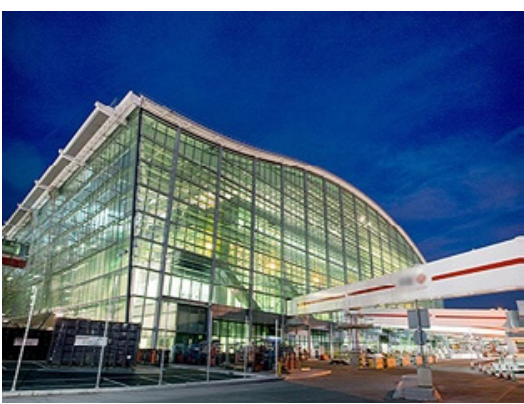

Londres-Heathrow. Terminal 5. Año 2008 http://www.transportplanning.mottmac.com/projects/ aviationservices/terminal5/

Paradójicamente, este aspecto nos lleva a señalar que en numerosos aeropuertos globales se repiten, replican, incluso emulan, los patrones de carácter cultural y morfológico que pueden apreciarse en otros hitos arquitectónicos urbanos. Forma, apariencia y diseño de esta infraestructura, además de constituir la primera impresión que recibe un visitante, suelen estar cuidadosamente preparados para proyectar una imagen atractiva, moderna, innovadora, competitiva, en definitiva global, de la ciudad, región, incluso el país ${ }^{10}$.

De manera sintética, se observa cómo las antiguas «cajas de hormigón» de formas rectilíneas y ángulos de 90 grados dan paso a formas curvas, desequilibrios geométricos y a la utilización de materiales exóticos, entre otros elementos. Así, se pueden destacar las cubiertas onduladas que superan la horizontalidad en Beijing-Capital (obra de Foster), Shangai-Pudong (Rogers), Osaka-Kansai (Piano) o Washington-Dulles (Saarinen); los muros de cristal que posibilitan la entrada total de luz en Londres-Heathrow (Rogers), HongKong-ChekLapKok (Foster) o Dubái International (Andréu). Además, se puede mencionar la utilización de criterios alegóricos en Londres-Stansted (árboles de estructuras de acero), Nueva York-JFK (pájaro con alas abiertas) y Bilbao-Sondika (ave alzando el vuelo); materiales singulares como el bambú en la cubierta de la T4 de ASMadrid-Barajas (Rogers) o el teflón de fibra de vidrio en Denver International (Bradburn).

A su vez, este factor de representatividad e imagen se viene desarrollado en las actividades auxiliares del aeropuerto, donde las tiendas tax free proyectan elementos de pertenencia a lo «global» a través de las grandes marcas que son, en sí, un fenómeno, también fácilmente visible en cualquier gran centro comercial. De esta manera, los enormes halls aeroportuarios,

10 Debe decirse, que la arquitectura de vanguardia también está recibiendo críticas y llega a ser considerada un elemento de homogeneización urbana. Autores como McNeill (2000) y Muñoz (2008) denominan este fenómeno como «McGuggenizacion» o «Urbanalización», respectivamente. No obstante, en este trabajo se valora únicamente la intención con que se construyen los edificios, que es el proyectar imágenes de modernidad. 


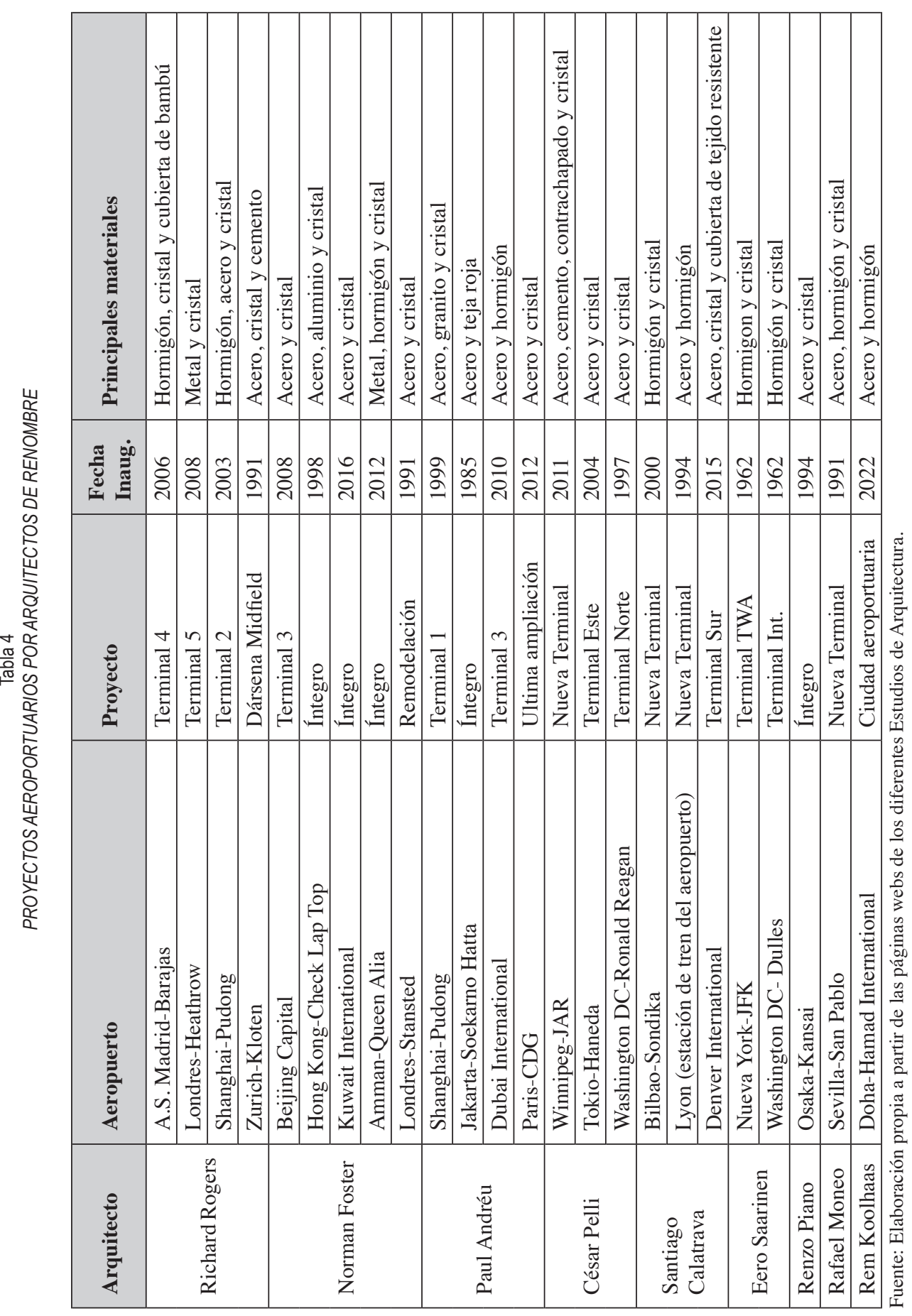


las salas de espera o las instalaciones duty free, son además centros comerciales, shopping centres o malls donde como en otros tantos, se escenifican los patrones intangibles de la globalización cultural a través de una gran teatralización del lugar (disneyzación), si bien adaptada a las singularidades locales (glocalización).

Cabe recordar que las «marcas globales», con sus iconos, se han convertido en un patrón de referencia a escala mundial, estando apoyadas en sistemas transnacionales de producción y de marketing, lo que las hace reconocibles a nivel universal, al tiempo que muchas de ellas son signo de cosmopolitismo y distinción (Lipovetsky, 2006). Gran parte pertenecen a los sectores de la moda, la restauración y el lujo, como puede apreciarse en la Tabla 5; además, pueden ser consideradas patrones inmateriales de la globalización cultural y, al tiempo, proyectan una escenificación del lugar donde se ubican, lo que contribuye a la estandarización globalizada de las localizaciones (uniformización, macdonalizacion).

En relación con lo anterior, a raíz del desarrollo de las actividades vinculadas al consumo, lo comercial se convierte en pretexto y finalidad para la ocupación del tiempo libre de los pasajeros. Como consecuencia de los tiempos de espera que se tienen que soportar, no extraña que los aeropuertos hayan participado en este lucrativo negocio de las compras, incrementando ostensiblemente sus beneficios, pues los usuarios son vistos más como compradores que como viajeros (Geouens et al., 2004). Paradójicamente un espacio como el aeropuerto, concebido para facilitar la movilidad se convierte en un destino turístico más, cuyo diseño está preparado para el ocio y el consumo y donde se intenta retener el más tiempo posible a las personas; se trata, en cierta medida de «espacios de inmovilidad». Así, aeropuertos como Heathrow, Chicago, Los Ángeles o Singapur-Changi, se han convertido en destinos de compras, operando como centros comerciales (air-malls) privilegiados de la ciudad (Adey, 2007).

Conviene también recordar que una parte de los pasajeros tiene un nivel adquisitivo alto o muy alto, y por tanto, el consumo de marcas de lujo forma parte de su identidad social (Hannerz, 1990 Geuens et al, 2004; Perng et al., 2010). Estudios recientes avalan esta idea (Amadeus - Oxford Economics, 2014); ya ha sido señalado que los negocios realizados «cara a cara» (face to face bussiness) en vez de descender tienden a estabilizarse en los años venideros; consecuentemente, el área de negocio basado en usuarios de clases bussiness, premium o similar ha crecido por encima de la clase turista, mientras que el sector aéreo considera que la demanda de estos usuarios en vez de descender se mantendrá. Por último, las motivaciones de gran parte de los desplazamientos (turismo, negocios, visita a familiares y amigos) tienden a ser consideradas cada vez más actividades experienciales (búsquedas de experiencias), lo que refuerza la necesidad de un enfoque integral de la cadena de valor del viaje.

En este sentido, el ocio forma parte de esta voluntad de seducción hacia el viajero, donde además de encontrarnos con tiendas de revistas, fast food y duty free, se generalizan otros equipamientos que evidencian las transformaciones recientes que se viven en los aeropuertos. Entre los ejemplos de estos cambios, que consideramos relacionados con las dinámicas de disneyzación (Bryman, 1999; Córdoba, 2009), se pueden mencionar los centros comerciales cada vez más lujosos (aeropuerto de Dubai), cines, saunas y piscinas (Singapur-Changi), museos (Las Vegas-McCarran), galerías de arte (Ámsterdam-Shiphol y Denver-Int.) y salas de juego (Las Vegas-McCarran); también, en la T5 del Londres-Heathrow, sofás y camas han reemplazado a los sillones y algunas salas de silencio permiten al viajero echar una siesta entre dos vuelos (Figura 3). 


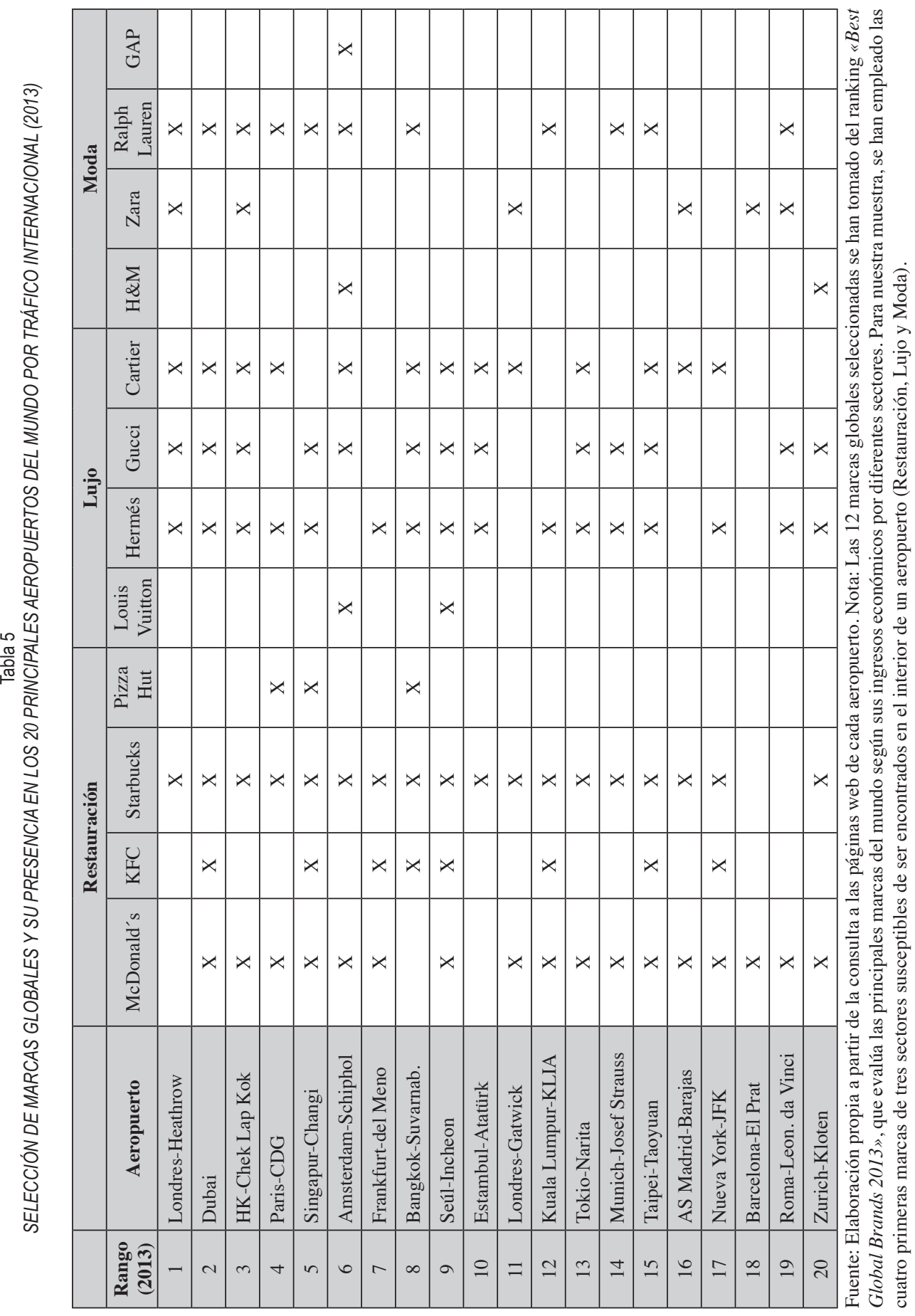




\section{Figura 3}

NUEVAS ACTIVIDADES LÚDICO-ECONÓMICAS EN LOS AEROPUERTOS

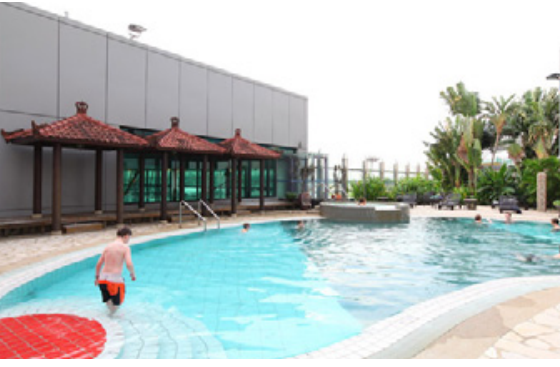

Piscina (Azotea Terminal 1). Singapur-Changi http://gianmarcolemura.tumblr.com/page/2

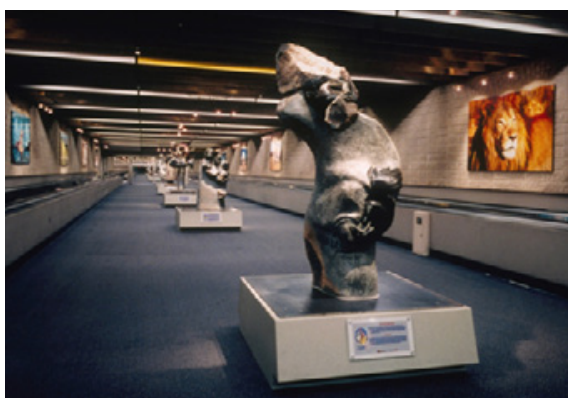

Galería de arte (Concorse T-A). Atlanta-Hartsfield http://www.atlanta-airport.com/HJN/2009/08/ passenger $1 . h t m$

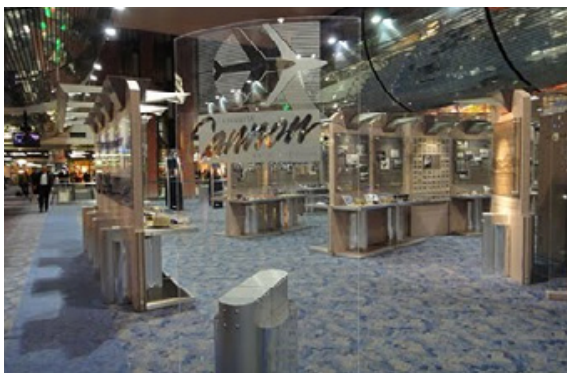

Museo de Aviación. Las Vegas-McCarran http://www.tour-beijing.com/blog/tag/chengduairport-shuttle-bus/

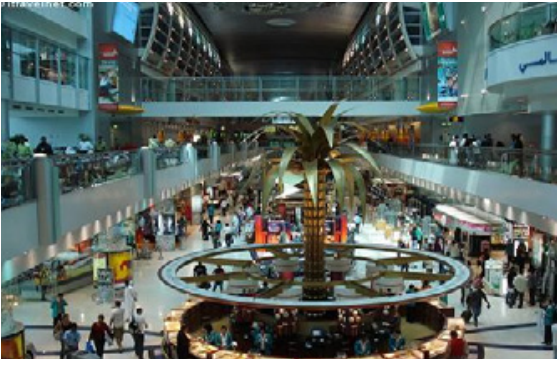

Centro Comercial (Terminal 3). Abu Dhabi http://kb2008blog.blogspot.com.es/2008/07/why-dowe-spend-money-at-airport.html

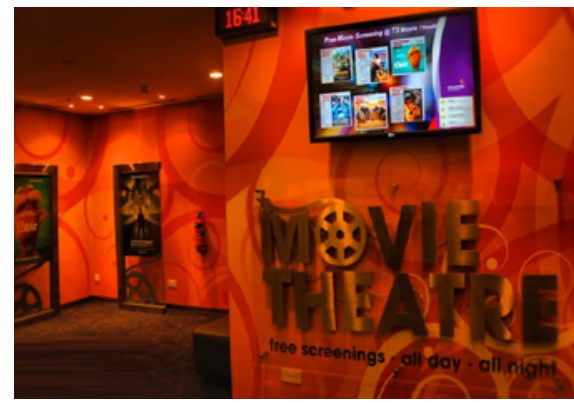

Sala de cine (Terminal 3). Singapur-Changi http://www.travelandbeyond.org/2012/10/10/thingsto-do-on-transit-at-changi-airport/

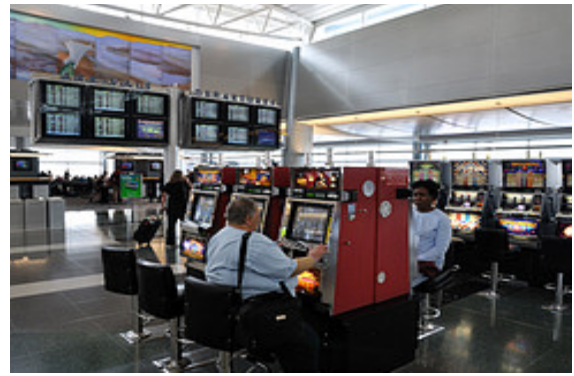

Sala de Juego. Las Vegas-Mc Carran

http://www.brisbanetimes.com.au/news/travel/beijingopens-27b-terminal/2008/02/29/1204226971512.html 


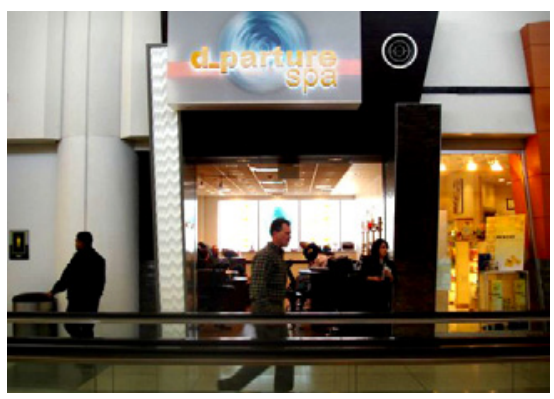

Centro de Spa (Terminal C). NY-Newark http://www.inc.com/business-travel-2011/bestairport-spa.html

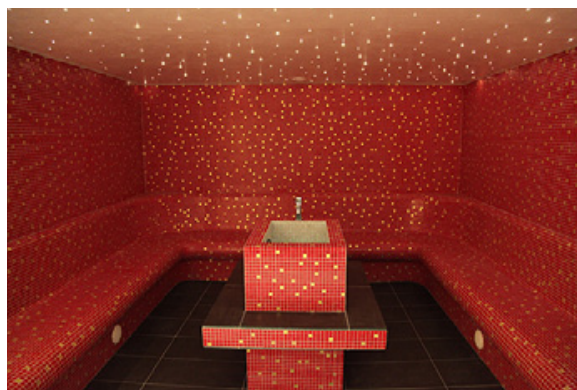

Sauna-Fitness. Zurich-Airport http://airport-fitness.ch/ENG/wella.htm

La dualidad que se establece en las ciudades globales entre la homogeneización y la singularización también se observa en las infraestructuras aeroportuarias. En este sentido algunos autores interpretan el hecho como una relación dialéctica, ligada a las sociedades de consumo, donde el acceso a los bienes y servicios debe estar suficientemente generalizada para obtener beneficios y, al mismo tiempo, los usuarios tienen la impresión de estar ante experiencias singulares en el proceso de adquisición, ya que precisamente éstas últimas son el estímulo que genera consumo (Harvey, 2013).

Esta dinámica ha abierto una línea de explicación ligada al concepto de «economía de la experiencia» (Pine y Gilmore, 1999). El primero de estos autores ofrece un ejemplo respecto al tipo de experiencia que se intenta recrear, utilizando un símil tan cotidiano como beber una taza de café: «el hecho de tomarnos un café ya es lo de menos. Ahora nos ofrecen experiencias, una decoración exuberante, recordando la vieja Venecia, con unos tapices dignos de ser elogiados, etc. Y todo ¿para qué? Para tomar café ¡Y a qué precios!» (Tarí Gil, 2003: 1).

Con esta intención, pueden observarse intentos de particularización de los aeropuertos, como forma de «hacer sentir a los pasajeros», donde la cultura local se convierte en un aliado en las prácticas de citybranding. Autores como Robertson (1992), Tomlinson (2001) o Friedman (2006) sitúan la cultura y la identidad como factores esenciales que se oponen a patrones de homogeneización cultural. Nogué y Vicente (2001) también se refieren a la revalorización de los lugares en el contexto posmoderno.

De esta manera, frente a la homogeneización de las actividades que se suceden en un aeropuerto (facturaciones, control de pasaportes, marcas globales similares que teatralizan los interiores, etc.), se asiste a un fenómeno de particularización o «exaltación de la especificidad del lugar», tanto en el interior como en el exterior de la infraestructura, poniendo de manifiesto el dualismo global-local. Por ello muchos autores los consideran lugares clave dentro de la interacción «global-local» (Haubermann et al., 2007). En este sen- 
tido, el aeropuerto se podría considerar un llamado lugar «glocal» (Swyngedouw, 1997), donde la imbricación y la interdependencia macro-micro son particularmente evidentes.

Pueden encontrarse ejemplos de lo dicho en los edificios aeroportuarios y en las diferentes actividades que estos albergan. Respecto a la arquitectura, dependencias que tienen una funcionalidad, forma y apariencia similar independientemente de la localización geográfica (zonas de gestión de equipajes, de llegada y salida, de descanso y espera, de compras, etc.) empiezan a adquirir ciertas señas de identidad que les permiten singularizarse dentro de la corriente homogeneizadora de la denominada «arquitectura ecléctica de vanguardia» (Markusen y Shock, 2006; Knox, 2012). Así, se adoptan criterios arquitectónicos que hacen referencia a la cultura autóctona (motivos, formas y colores), lo que permite al pasajero identificar el edificio con el lugar, región o país donde se ubica.

Siguiendo esta interpretación, Edwards (2004) analiza la imagen «memorable» según sus palabras, de los aeropuertos de Denver (Estados Unidos) e Incheon (Corea del Sur). Para el primer caso, las Montañas Rocosas sirvieron de inspiración en la forma dada a la cubierta de la terminal de pasajeros, de fibra de vidrio revestida de teflón, que simboliza el patrimonio montañoso de la ciudad. En el segundo, la cultura coreana se muestra con un diseño inspirado en un hogar coreano tradicional, con figuras de animales y costumbres nativas, constituyendo un museo funcional y simbólico de la historia del país. En ambos casos, los aeropuertos imitan formas con las cuales se los pretende identificar con sus respectivas localizaciones (Figura 4a y 4b).

Se pueden aludir otros ejemplos, como la cubierta de la Terminal 4 del Adolfo Suárez Madrid-Barajas, realizada en madera de bambú, que resalta la horizontalidad meseteña sobre la que se asienta gracias a las curvaturas de su cubierta, «una alfombra voladora que acompaña a los viajeros en su tránsito por el aeropuerto» (Figura 4c); o la techumbre del aeropuerto de Beijing, obra de Foster, que recuerda la morfología de un dragón en alusión a uno de los máximos emblemas de la cultura china (Figura 4d). Dos de los casos más recientes, también propuestos por Norman Foster, tienen en su diseño las mismas pretensiones. Así, la planta del nuevo aeropuerto de Ciudad de México, tendrá forma de «X», en referencia a la palabra México; y el recién reinaugurado de Amán imita las «geometrías de la cultura árabe» (Figura 4e y 4f).

La identidad local se escenifica, también, en aquellos establecimientos del aeropuerto que ofrecen productos propios del país o la región, como son las especialidades gastronómicas, los souvenires o las artesanías locales, entre otros. Algunos ejemplos de estas adaptaciones son las panaderías francesas en Paris-CDG (Figura 5a), las tiendas de chocolate belga en Bruselas (Figura 5b), las relojerías y joyerías en Ginebra-Cointrin (Figura 5c) o las ventas de los conocidos alfajores argentinos en Buenos Aires (Figura 5d). Con esta misma lógica, algunas cadenas de restaurantes incluyen adaptaciones a la cultura local. Podemos mencionar el McDonald's kosher del Tel Aviv Ben-Gurion; o el letrero del Starbucks coffee en Montreal-Trudeau, que es sustituido por la versión en francés «Café Starbucks».

A parte de restaurantes y comercios, se ofrecen otro tipo de experiencias que ponen el acento en la diversión, el ocio y la relajación, y que han revolucionado la «anodina» sala de espera. En Suvarnabhumi-Bangkok, la cadena Royal Orchid Spa tiene uno de sus establecimientos dentro del recinto, donde se ofertan masajes tradicionales tailandeses; incluso la 
Figura 4

EJEMPLOS DE GLOCALIZACIÓN AEROPORTUARIA

(ARQUITECTURA DEL AEROPUERTO)

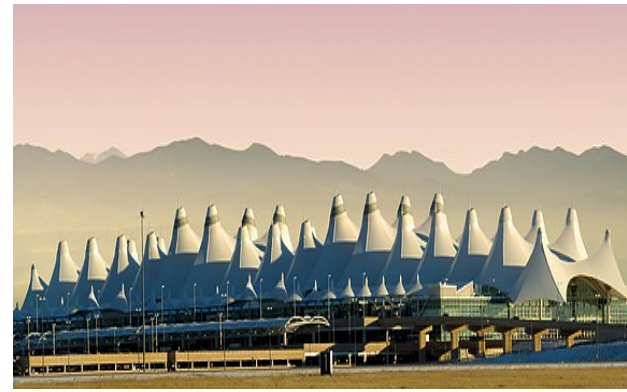

4a. Montañas Rocosas (Denver-International)

http://www.slrobertson.com/galleries/usa/colorado/htm

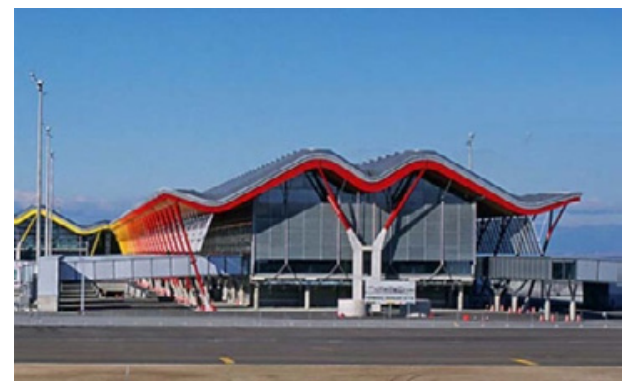

4c. Alfombra voladora (T4 AS. Madrid-Barajas) http://hoteles4you.com/blog/la-t4-y-la-t4s-seranremodeladas.html

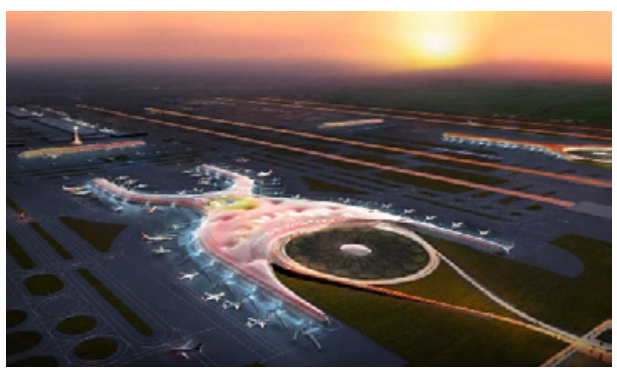

4e. Letra «X» (Futuro aerop. Ciudad de Méx.) http://www.mosingenieros.com/2014/09/futuroaeropuerto-mexico.html

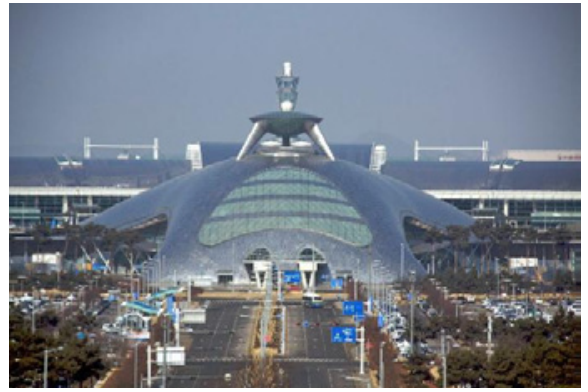

4b. Hogar tradicional coreano (Seúl-Incheon) http://www.jetsetz.com/cheap-seoul-flights-inc

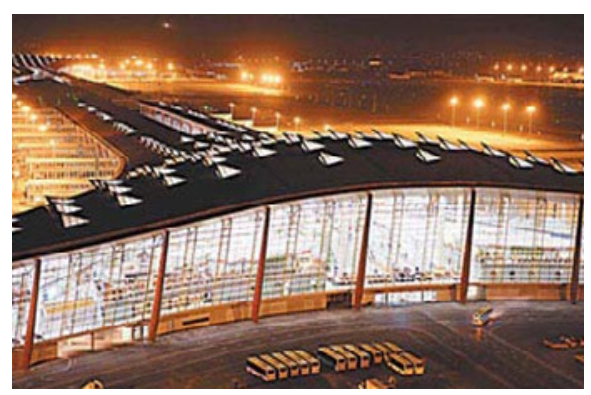

4d. Dragón (Beijing-International)

http://english.people.com.

cn/90001/90776/90882/6448275.html

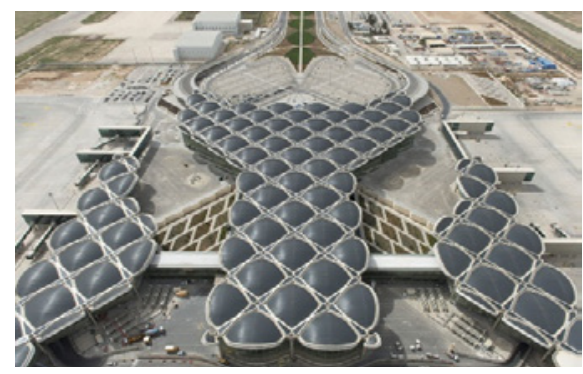

4f. Geometrías de la cultura árabe (Aerop. Amán) http://arqa.com/arquitectura/internacional/aeropuertoqueen-alia-en-amman-jordania.html 


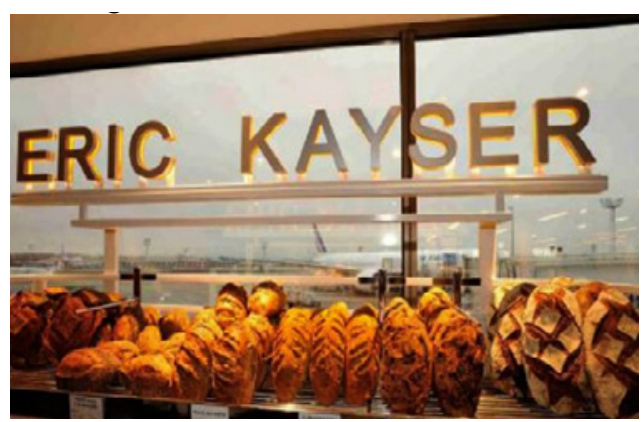

5a. Panadería Eric Kayser (París-CDG)

http://www.aeroportsdeparis.fr/ADP/fr-FR/Passagers/ Boutiques-Services/

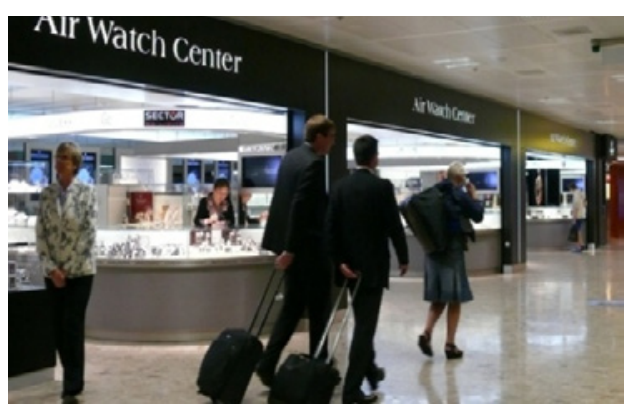

5c. Air Watch Center (Ginebra-Airport) http://www.gva.ch/en/desktopdefault.aspx/ tabid-146/449_read-409/

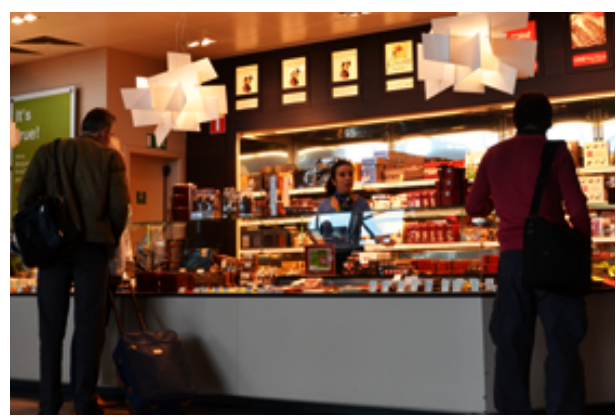

5b. The Chocolate Company (Bruselas-Airport) http://www.brusselsairport.be/en/passngr/shops/ pier_a/shopping/4671/

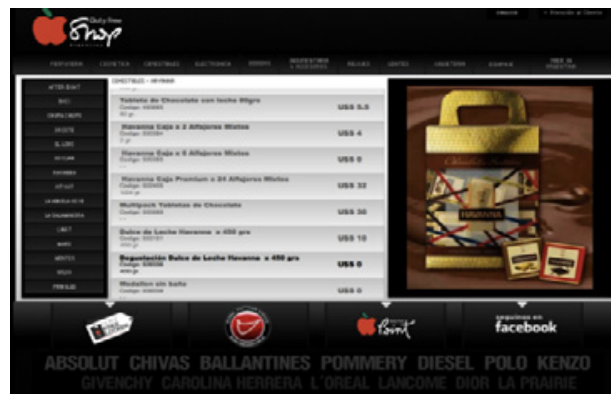

5d. Alfajores. Int. Jorje Newbery (Buenos Aires) http:// www.aena-aeropuertos.es

principal compañía del país regala el servicio a clientes de primera clase (Figura 6a). En las Vegas-McCarran se localizan máquinas tragaperras en algunos de sus corredores para que los viajeros continúen experimentando el ambiente de los casinos (Figura 6b). El hall de llegadas del Aeropuerto de Auckland da la bienvenida a los pasajeros internacionales en un ambiente recreado en «la Tierra Media», en referencia al libro de Tolkien, El Señor de los Anillos (Figura 6c). En el restaurante Sushi Kyotatsu de Narita-Tokio el pasajero puede «disfrutar de los gustos tradicionales de Japón antes de abandonar el país en un escenario único» (Figura 6d). Por último, cabe mencionar que en Singapur-Changi varios jardines permiten encontrarse con la fauna y flora del Sudeste Asiático (girasoles, mariposas...) sin salir del recinto (Figura 6e y 6f). Lohmann et al. (2009) destacan, en referencia a este último ejemplo, que ya no sólo se utilizan souvenirs o productos locales como elementos identitarios, sino que en este caso elementos vivos, como la vegetación y la fauna, se convierten en los agentes de la experiencia aeroportuaria. 
Figura 6

EJEMPLOS DE EXPERIENCIAS EN LOS AEROPUERTOS

BASADAS EN EL OCIO Y LA RELAJACIÓN

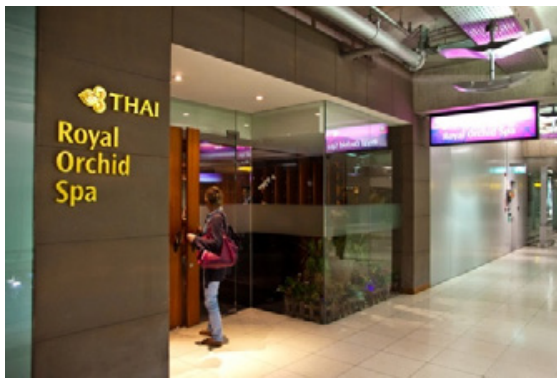

6a. Royal Orchid Spa (Suvarnab.-Bangkok)

http://www.flyertalk.com/forum/22885961-post26.html

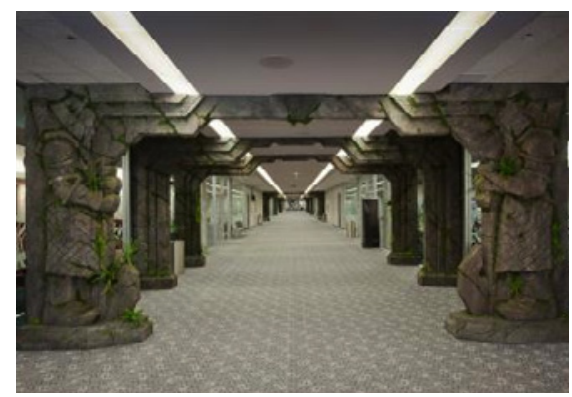

6c. Hall de llegadas (Auckland-Int.)

http://www.changiairport.com/at-changi/leisureindulgences/nature-trail

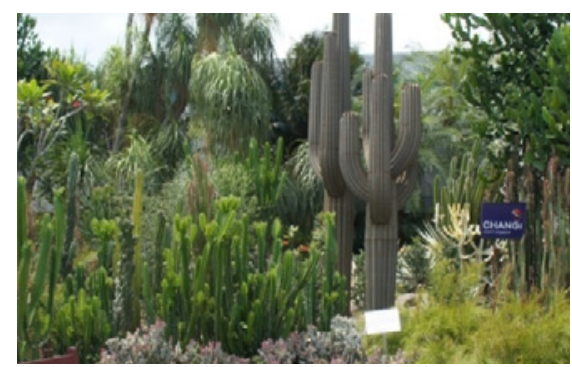

6e. Jardín de Cactus (Singapur-Changi; T1)

http://www.changiairport.com/at-changi/leisureindulgences/nature-trail

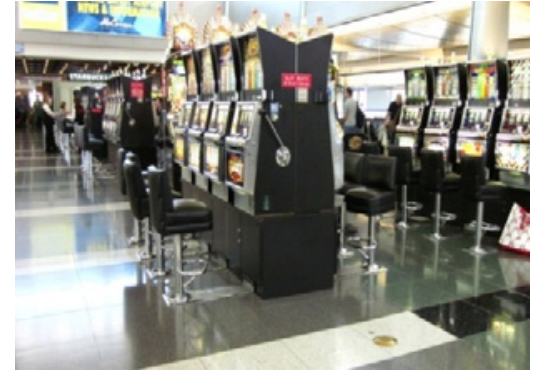

6b. Sala de Juego (Las Vegas-Mc Carran)

http://www.menudeviaje.com/2013/09/30/ir-a-las-vegas/

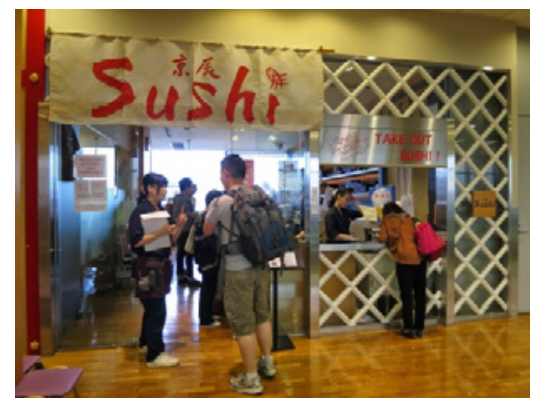

6d. Sushi Kyotatsu (Narita-Tokio)

http://www.changiairport.com/at-changi/leisureindulgences/nature-trail

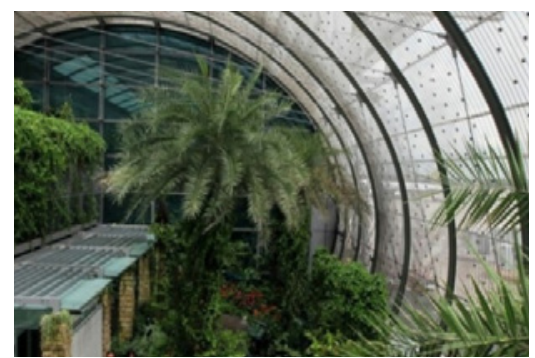

6f. Jardín de mariposas (Singapur-Changi; T3) http://www.changiairport.com/at-changi/leisureindulgences/nature-trail

\section{CONCLUSIONES}

El análisis anterior ha puesto de manifiesto la importancia que tienen los aeropuertos como vectores de la movilidad contemporánea y puede decirse, por tanto, que deben ser 
considerados «lugares de la Globalización». Estas infraestructuras son cada vez más utilizadas por un creciente número de usuarios, que en la actualidad ronda los tres mil millones de pasajeros anuales (IATA, 2012). Sin embargo, su significado va más allá del movimiento de personas y mercancías que en ellos se produce, ya que como se ha visto, se han convertido en símbolos del modo de vida actual. Así, se ha podido constatar como los usos no aeronáuticos tienen cada vez más presencia en estos lugares, lo que ha ocasionado un cambio de concepción en su diseño y en las actividades que se desarrollan.

Los cambios morfológicos, asociados a arquitecturas vanguardistas se interpretan, además, como iniciativas de citymarketing. Con ellas se pretende fortalecer una imagen moderna, prestigiosa, atractiva, innovadora, en definitiva, global, de los territorios en donde se localizan, pues constituyen una puerta de entrada fundamental a un país o a una ciudad. No debe extrañar, por tanto, las grandes inversiones que se han realizado en muchas de estas infraestructuras aunque, a nuestro juicio, consideramos que la funcionalidad aeroportuaria nunca debe quedar soslayada en favor de la estética vanguardista. Si acaso, debiera complementarse de manera conjunta, teniéndose en cuenta que las inversiones de remodelación deben ser razonables y ajustadas a unas necesidades probadas.

Por otro lado, los aeropuertos se han convertido en escenarios de las prácticas de ocioconsumo, con similares características a las de cualquier centro comercial. Así se facilita que este tipo de actividades continúen casi hasta el momento de embarque. En este sentido, resulta común observar, marcas globales (muchas de ellas de lujo), productos de consumo (tabaco, licores o chocolates), restaurantes temáticos, establecimientos de souvenirs y artesanías o restaurantes de especialidades locales. Además en algunos casos, tanto las actividades que se desarrollan como las arquitecturas que las albergan tienden a exagerarse en términos de modernidad, lujo, exclusividad, eficiencia y singularidad, puesto que son uno de los referentes fundamentales a la hora de proyectar la imagen de la ciudad y del país.

También, se ha puesto de manifiesto el enorme papel que a la hora de proyectar identidades territoriales se ha conferido a los aeropuertos, pese a la homogeneización que imprime la réplica de arquitecturas con patrones vanguardistas y las actividades de ocio-consumo que se llevan a cabo. Estas infraestructuras son un ejemplo de la necesidad de singularizar y de exhibir aquellos elementos diferenciadores en un contexto de competitividad urbana; por tanto, deben ser considerados elementos esenciales en la consolidación de las ciudades mundiales, no solo por ser infraestructuras de movilidad, sino también por las connotaciones simbólicas y experienciales que han adquirido. Así, aeropuerto y ciudad están en simbiosis continua, en un contexto de pugna entre ciudades por atraer cuantos más visitantes, ideas, capitales, en definitiva, todo tipo de flujos, sea posible.

\section{BIBLIOGRAFÍA}

ADEDIBU, A. (1977): Spatial diffusion analysis of commercial land use changes associated with the Jacksonville, Florida, International Airport (1965-1976). Tesis doctoral. Gainesville: Unv. Florida.

ADEY, P. (2007): «May I have your attention»: airport geographies of spectatorship, position, and (im)mobility». Environment and Planbning D: Society and Space, vol. 27, pp. 515-536. 
AMADEUS (2005): Future Traveler Tribes 2020. Henley Centre Headlight Vision. Disponible en: www.amadeus.com/web/.../TravellerTribes,2.pdf.

AMADEUS Y OXFORD ECONOMICS (2014): The Travel Gold Rush 2020. Disponible en: http://www.amadeus.com/amadeus/documents/corporate/Travel-Gold-Rush-2020-EN. pdf

ANTÓN, F.J. (1992): «El sistema «hub and spoke» en el transporte aéreo». Anales de Geografía de la Universidad Complutense, 2, pp. 111-124.

BAUMAN, Z. (2001): La globalización. Consecuencias humanas. México, FCE.

BAZARGAN, M., y VASIGH, B. (2003): «Size versus efficiency: a case study of US commercial airports». Journal of Air Transport Management, 9 (3), pp. 187-193.

BEL, G. y FAGEDA, X. (2008): «Getting There Fast: Globalization, Intercontinental Flights and Location of Headquarters», Journal of Economic Geography, 8 (4), pp.471-95.

BOWEN, J. (2000): «Airline hubs in Southeast Asia: national economic development and nodal accessibility». Journal of Transport Geography, 8 (1), pp. 25-41.

BOWEN, J. y CIDELL, J. (2011): «Mega-Airports: The Political, Economic, and Environmental Implications of the World's Expanding Air Transportation Gateways». En S.D. Brunn (Ed.) Engineering Earth: The Impacts of Megaengineering Projects, Dordrecht: Kluwer Academic Publishers, pp. 867-887.

BRUECKNER, J. y ZHANG, Y. (2001): «A model of schedulin in airline networks. How a hub-and-spoke system affects flight frequency, fares and welfare». Journal of Transport Economics and Policy, 35 (2), pp. 195-222.

BRYMAN, A. (1999): «The Disneyzation of Society». The Sociological Review, 47 (1), pp. 25-47.

BUDD, L. (2012): «Airport: from flying fields to twenty first century aerocities». En: DERUDDER ET AL. (Eds.): Int. Handbook of Globalization and World Cities. Cheltenham: Edward Elgar Pub.

BUTTON, K., LALL, S., STOUGH, R., y TRICE, M. (1999): «High-technology employment and hub airports». Journal of Air Transport Management, 5(1), pp. 53-59.

CAMAGNI, R. (2003): «On the concept of territorial competitiveness: sound or misleading?», Urban Studies, 39 (13), pp. 2395-2411.

CANOSA, E. y GARCÍA CABALLERO, A. (2012): «La construcción de la marca Madrid». Cuadernos Geográficos, 51 (2), pp. 195-221.

CIDELL, J. (2006): «Air Transportation, Airports, and the Discourses and Practices of Globalization», Urban Geography, 27 (7), pp. 651-63.

CÓRDOBA, J. (1980). El Aeropuerto de Madrid-Barajas: estudio geográfico. Tesis doctoral. Madrid: Universidad Complutense.

CÓRDOBA, J. (2009): «Turismo, desarrollo y disneyzación: ¿Una cuestión de recursos o de ingenio?». Investigaciones Geográficas, 70, pp. 33-54.

CÓRDOBA, J., GAGO, C., y SERRANO, M. (2007). «Transporte aéreo y espacialidad diferencial». En: S. GUTIÉRREZ Y J. J. SANZ (Eds.), Homenaje al Profesor José Manuel Casas Torres. Madrid: Universidad Complutense, pp. 45-64.

CÓRDOBA, J. y GAGO, C. (2010): «Latin American cities and globalisation: change and permanency in the context of development expectations». Urban Studies, 47 (9), pp. 2003-2021. 
CÓRDOBA, J. y GAGO, C. (2012): «Globalización, movilidad y análisis de conectividad aérea: una herramienta para la práctica interdisciplinar». Revista de Antropología Social, 21, pp. 117-146.

DERUDDER, B., y WITLOX, F. (2005a): «An appraisal of the use of airline data in assessing the world city network: a research note on data». Urban Studies, 42 (13), pp. 23712388.

DERUDDER, B., y WITLOX, F. (2005b): «On the use of inadequate airline data in mappings of a global urban system». Journal of Air Transport Management, 11, pp. 231-237.

DERUDDER, B., DEVRIENDT, L. y WITLOX F. (2007): «Flying where you don't want to go: an empirical analysis of hubs in the global airline network». Tijdschrift voor economische en sociale geografie, 98, pp. 307-324.

DERUDDER, B., y WITLOX, F. (2008): «Mapping world city networks through airline flows: context, relevance, and problems». Journal of Transport Geography, 16 (5), pp. 305-312.

DVIR, R. y PASHER, E. (2004): «Innovation engines for knowledge cities: an innovation ecology perspective». Journal of Knowledge Management, 8 (5), pp. 16-27.

ECA (2014): «EU-funded airport infrastructures: poor value for money», Special Report. European Court of Auditors, Disponible en: http://www.eca.europa.eu/Lists/ECADocuments /SR14_21/QJAB14021ENC.pdf. Fecha de la consulta: 24/07/2015.

EDWARDS, B. (2004). The modern airport terminal: New approaches to airport architecture. Nueva York, Taylor \& Francis.

FREATHY, P. (2004): «The commercialisation of European airports: successful strategies in a decade of turbulence?». Journal of Air Transport Management, 10 (3), pp. 191-197.

FREESTONE, R. (2011): «Managing Neoliberal Urban Spaces: Commercial Property Development at Australian Airports». Geographical Research, 49 (2), pp. 115-131.

FRIEDMAN, T. (2006): La tierra es plana: Breve historia del mundo globalizado del siglo XXI. Madrid: Martínez Roca.

FUENTES, L. (2011): "Competitividad urbana en el contexto latinoamericano. El caso de Santiago de Chile». Revista de Geografía Norte Grande, 48, pp. 81-106.

FULLER, G. y HARLEY, R. (2004): Aviopolis. London: Black Dog Publishing Ltd.

GAGO, C. (2003): Región, Política y Transporte aéreo. Madrid: Universidad Complutense.

GAGO, C., SERRANO, M. y DÍEZ PISONERO, R. (2015):»Aeropuertos, desarrollo y cambios de usos del suelo en ciudades». En: ESPINOSA, A. y ANTÓN, F.J. (Eds.), El papel de los servicios en la construcción del territorio. Alicante: AGE- Grupo de Geografía de los Servicios, pp. 653- 671.

GEUENS, M., VANTOMME, D., y BRENGMAN, M. (2004): «Developing a typology of airport shoppers». Tourism Management, 25 (5), pp. 615-622.

GRAHAM, A. (2009): «How important are commercial revenues to today's airports?», Journal of Air Transport Management, 15, pp. 106-111.

GÜLLER, M. y GÜLLER, G. (2003): From Airport City to Airport City. Barcelona: Gustavo Gili.

HAKFOORT, J., POOT, T., y RIETVELD, P. (2001): «The regional economic impact of an airport: the case of Amsterdam Schiphol Airport». Regional Studies, 35(7), pp. 595-604. 
HANNERZ, U. (1990): «Cosmopolitans and locals in world culture». Theory, culture and society, 7 (2), pp. 237-251.

HARVEY, D. (1998): La condición de la posmodernidad: investigación sobre los orígenes del cambio cultural. Buenos Aires-Madrid: Amorrortu.

HARVEY, D. (2013): Ciudades rebeldes. Madrid. AKAL.

HAUBERMANN, H., LÄPPLE, D. y SIEBEL W. (2007): Stadtpolitik. Frankfurt, Suhrkamp.

IATA (International Air Transport Association, 2012). Resultados económicos de la industria aérea de aerolíneas. Disponible en: https://www.iata.org/pressroom/pr/Documents/PressRelease-no-30-2014-06-02-sp.pdf. Fecha de la consulta: 10/04/2013.

JENCKS, C. (2006): «The iconic building is here to stay». City, 10 (1). Pp. 3-20.

JESSOP, B. y SUM, N. (2000): «An entrepreneurial city in action: Hong Kong's emerging strategies in and for (inter) urban competition». Urban studies, 37 (12), pp. 2287-2313.

JESSOP, R. (2003). The Future of the Capitalist State. Cambridge: Polity Press.

KASARDA, J. (2001): «From Airport City to Aerotropolis». Airport World, 6, pp. 42-47.

KEELING, D. (1995): «Transport and the world city paradigm». En: P.L. KNOX, P.J. TAYLOR (Eds.), World Cities in a World-system. Cambridge, Cambridge University Press, pp. 115-131.

KNOX, P. (2012): «Starchitects, starchitecture and the symbolic capital of world cities». En: DERUDDER ET AL. (Eds). Int. Handbook of Globalization and World Cities. Cheltenham: Edward Elgar Pub, pp. 275-283

KRAFFCZYK, D. (2012): The Aeroscape: An approximation. Disponible en: http://aeroscape.org/2013/04/22/the-aeroscape-an-approximation/. Fecha de la consulta: 14/12/2013.

LIPOVETSKY, G. (2006): Los tiempos hipermodernos. Barcelona, Anagrama.

LIPOVICH, G. (2012): «La calidad de los hubs de América Latina». Journal of Transport Literature, 6 (2), pp. 144-168.

LOHMANN, G., ALBERS, S., KOCH, B., y PAVLOVICH, K. (2009): «From hub to tourist destination - An explorative study of Singapore and Dubai's aviation-based transformation». Journal of Air Transport Management, 15 (5), pp. 205-211.

MARKUSEN, A. y SCHROCK, G. (2006): «The distinctive city: divergent patterns in growth, hierarchy and specialization». Urban Studies, 43 (8), pp. 1301-1323.

MAYUR, A. ET AL. (2013): «The land use pattern changes due to establishment of Bangalore International Airport». Global Journal of Biology Agriculture and Health Sc., 2 (2), pp. 34-37.

McNEILL, D. (2000): «McGuggenisation: globalisation and national identity in the Basque country». Political Geography, 19, pp. 473-494.

MILES, S. (2012): «The neoliberal city and the pro-active complicity of the citizen consumer». Journal of Consumer Culture, 12 (2), pp. 216- 230.

MOULAERT, F., SWYNGEDOUW, E., MARTINELLI, F., y GONZALEZ, S. (Eds.). (2010). Can neighbourhoods save the city?: community development and social innovation. London: Routledge.

MUÑOZ, F. (2008): Urbanalización. Paisajes comunes, lugares globales. Barcelona, Gustavo Gili.

NEUFVILLE, R., y YAJIMA, T. (1972): Economic Impact of Airport Development. Boston: MIT Civil Engineering Systems Laboratory. 
NOGUÉ, J. y VICENTE, J. (2001): Geopolítica, identidad y globalización. Barcelona: Ariel. PEDREÑO, A. (2006): «Los aeropuertos, la estrategia territorial y los vuelos baratos. Utopías y realidades». Disponible en: http://utopias-realidades.blogspot.com.es/2006/04/losaeropuertos-la-estrategia.html. Fecha de la consulta: 20/02/2014.

PERNG, S., CHOW, C. y LIAO, W. (2010): «Analysis of shopping preference and satisfaction with airport retailing products». Journal of Air Transport Management, 16(5). Pp. 279-283.

PLAZA, B. (2000): «Evaluating the Influence of a Large Cultural Artifact in the Attraction of Tourism. The Guggenheim Museum Bilbao Case». Urban Affairs Review, 36(2), pp. 264-274.

PLAZA, B., y HAARICH, S. (2010): «A Guggenheim-hermitage museum as an economic engine?». Transformation in Business \& Economics, 9 (2), pp. 128-138.

PORTER, M. (2002): «Regional foundations of competitiveness and implications for government policy». Paper presented at the Department of Trade and Industry Workshop on Regional Competitiveness, London.

ROBERTSON, R. (1992): Globalization: Social theory and global culture. Londres: Sage Pub.

SCHAAFSMA, M., AMKREUTZ, J., y GÜLlER, M. (2008): Airport and City. Airport Corridors: Drivers of Economic Development. Amsterdam: Schiphol Real Estate.

SCHLAAK, J. (2010): «Defining the Airea. Evaluating urban output and forms of interaction between airport and region». En: KNIPPENBERGER, A. W. (Eds.) Airports in Cities and Regions. Research and Practise. Karlsruhe: KIT Scientific Publishing, pp. 113-125.

SCOTT, A. J. (2008): Social Economy of the Metropolis: Cognitive-Cultural Capitalism and the Global Resurgence of Cities. Oxford: Oxford University Press.

SHANNON, K., y SMETS, M. (2010): The landscape of contemporary infrastructure. Rotterdam: NAi.

SMITH, D. y TIMBERLAKE, M. (2001): «World city networks and hierarchies, 1977-1997: an empirical analysis of global air travel links». American Behavioral Scientist, 44(10), pp. 1656-1678.

STORPER, M. (1997): The Regional World. New York: Guilford Press.

SWANGJANG, K. y IAMARAM, V. (2011): «Change of land use patterns in the areas close to the airport development area and some implicating factors». Sustainability, 3(9), pp. 1517-1530.

SWYNGEDOUW, E. (1997): «Neither global nor local: «Glocalization» and the Politics of scale». En: COX, K. R.. Spaces of Globalization. Nueva York: Guilford, pp. 137-166.

TARÍ GIL (2003): «En la Economía de la Experiencia, el trabajo es teatro». Entrevista a Joseph Pine por Sergio Tarí Gil. Disponible en: www.strategichorizons.com/.../ iWorld\%200305\%20Trabajo \%20es\%20T.

TIMBRELL, G., FOTH, M., y HEARN, G. (2006): «Towards Knowledge Management for Explorers: The Case of the Brisbane Airport Corporation». International Journal of Knowledge, Culture and Change Management, 6 (6), pp. 97-104.

TOMLINSON, J. (2001): Globalización y Cultura. México DF. Oxford University Press México.

VAN DENDER, K. (2007): «Determinants of fares and operating revenues at US airports». Journal of Urban Economics, 62(2), pp. 317-336.

VAN WIJK, M. (2008): «Development of airport regions: varieties of institutions in Schiphol and Frankfurt». Aerlines, e-zine edition, 40, pp. 1-5. 
WANG, K. y HONG, W. (2011): «Competitive advantage analysis and strategy formulation of airport city development-The case of Taiwan». Transport Policy, 18(1), pp. 276-288.

YEO, G., WANG, Y., y CHOU, C. (2013): «Evaluating the competitiveness of the aerotropolises in East Asia». Journal of Air Transport Management, 32, pp. 24-31.

YIGITCANLAR, T. (2008): Knowledge-based urban development: planning and applications in the information era. Nueva York: Information Science Reference. 
